\title{
Secondary Bioactive Metabolites from Plant-Derived Food Byproducts through Ecopharmacognostic Approaches: A Bound Phenolic Case Study
}

\author{
Ilaria Burlini and Gianni Sacchetti * \\ Department of Life Sciences and Biotechnology_Pharmaceutical Biology Lab., Research Unit 7 of the Terra \\ \& Acqua Tech Technopole Lab., University of Ferrara, P.le Chiappini 2, 44123 Ferrara, Italy; ilaria.burlini@unife.it \\ * Correspondence: gianni.sacchetti@unife.it
}

Received: 27 July 2020; Accepted: 14 August 2020; Published: 19 August 2020

\begin{abstract}
The climate emergency and the risks to biodiversity that the planet is facing nowadays, have made the management of food resources increasingly complex but potentially interesting. According to FAO, one-third of the edible parts of food produced throughout the whole food supply chain gets lost or wasted globally every year. At the same time, demographic growth makes it necessary to change course toward sustainable economic development in order to satisfy market demands. The European Union supported the idea of a Circular Economy from 2015 and arranged annual Action Plans toward a greener, climate-neutral economy. Following the biorefinery concept, food waste becomes byproducts that can be recovered and exploited as high added-value materials for industrial applications. The use of sustainable extraction processes to manage food byproducts is a task that research has to support through the development of low environmental impact strategies. This review, therefore, aims to take stock of the possibilities of extracting molecules from food waste biomass following ecopharmacognostic approaches inspired by green chemistry guidelines. In particular, the use of innovative hybrid techniques to maximize yields and minimize the environmental impact of processes is reviewed, with a focus on bound phenolic extractions.
\end{abstract}

Keywords: food waste; byproducts; green extractions; bound phenolics

\section{Introduction and Historical Background}

Food waste recovery has become a hot topic in the field of natural product and ecopharmacognosy research in the past 20 years: however, it should not be surprising that the development of this research topic was born in conjunction with a series of ideologies and historical evidence. From the early roots of Carl Linnaeus, Alexander von Humboldt, Alfred Russel Wallace, Charles Darwin, Ernst Haeckel and many more contributors, ecology has been recognized as a science and it started to spread all over the scientific world as the study of all those manifold interactions between organisms and their environment. From the first half of the 20th century, ecology has reshaped the position of the human being that has become a crucial part of the biological equilibrium of the planet, now conceived as a finite space: the idea that the planetary biomass is limited makes the life-with its fragile balances among multiple and complex interactions-incapable of eternal renewal and subjected to dangerous imbalances for the survival of all the species on Earth, mankind included [1]. In 1981, Walter R. Stahel began developing the idea of sustainability by supporting "service-life extension of goods-reuse, repair, remanufacture, upgrade technologically" or what is known today as a circular economy [2]. The purpose of a circular economy, now supported by the European Commission action plans from 2015, is shifting from the linear scheme "taking, making, consuming, throwing away" to a circular flow which maintains goods and resources in the production economy as far as possible, reducing environmental 
impacts while maximizing resource efficiency promoting what is now known as the "cradle to cradle" way of production for the supply chains [3]. The birth of Industrial Ecology, announced by Erkman in 1997, represents another useful tool for understanding the circular flows of materials and energy and, therefore, the creation of alternative managements through reuse, repair, recycling and remanufacturing for the recovery of components and extend their lifecycle [4]. The recovery of industrial byproducts and the study of their potential applications began already before the First World War, accentuated in the first postwar period with the increase in the prices of basic necessities and developing further from the middle of the last century [5]. However, a significant interest increase by academic research coincided, between the 1960s and 1970s, with a political awareness of the importance of minimizing waste (in that period Mobius Loop was introduced as a figurative expression of Reducing, Reusing, Recycling), thus a large number of publications about sustainable strategies of waste valorization enriched the literature [6]. The recent updates given by the world's leading climate science during the UN Intergovernmental Panel on Climate Change (IPCC) held at the end of 2018 regarding the environmental risks of the planet, pointed out that urgent and unprecedented changes are needed to avoid catastrophic environmental breakdown. The management of the planet's resources and wastes is, consequently, stimulating research to find useful and alternative strategies.

This review is focused on ecopharmacognostic approaches as opportunities to valorize food wastes/byproducts as sources of healthy and useful bioactives, giving a general overview of food wastes/byproducts general definitions, costs and current management, as well as promising examples of alternatives to petroleum-derived solvent extraction techniques. Conventional extraction processes are in many respects no longer sustainable in terms of energy consumption, environmental impact, solvent biodegradability and thus not effective in yields and selectivity [7]. The ecopharmacognostic approach to obtain bioactive molecules for applicative purposes-health included-is the way to go for a more sustainable production policy, respecting plant biodiversity through the best exploitation of plant resources.

\section{Food Losses and Wastes}

\subsection{Definitions}

The issues of food losses and wastes are of high importance as they are directly linked to the environment, economic development, food quality and safety and to food sustainability for developing countries. Hence, before going into the topic in detail, few essential definitions are given below. According to Fusions's "Estimates of European food wastes levels", "Food" is defined as "any substance or product, whether processed, partially processed or unprocessed, intended to be, or reasonably expected to be, eaten by humans. Food includes drink, chewing gum and any substance, including water, intentionally incorporated into food during its manufacture, preparation or treatment". In the same way, food wastes are considered as "fractions of food and inedible parts of food removed from the food supply chain to be recovered or disposed of through composted, crops plowed in/not harvested, anaerobic digestion, bioenergy production, cogeneration, incineration, disposal to sewer, landfill or discarded to sea" [8]. A difference in meaning between "food waste" and "food losses" is given by the Food and Agricultural Organization of the United Nations (FAO): the former is considered as food loss which occurs at the end of the food chain and is related to the behavior of retailers and consumers, whereas the latter takes place at production, postharvest and processing stages in the food supply chain [9].

\subsection{Types of Food and Waste (or ByProducts) Management}

There are five stages in the food life cycle where waste is generated from both animal and vegetable sources: (1) agricultural production, (2) postharvest handling and storage, (3) processing, (4) distribution and (5) consumption, considered and described in the following table. 
Until a few decades ago, food wastes were considered neither a cost nor a benefit: they were used as animal feed, brought to landfills or sent for composting. The growing environmental issues as well as the high disposal costs are two of the main reasons that brought countries to a more sustainable approach. According to the Directive 2008/98/EC, adopted by the New Waste Framework Directive, the prevention of waste generation has to be a priority, followed by processing for reuse and recycling, with disposal and landfill as the least favored stages of waste management (Figure 1). Vision 2020, launched by ReFood in 2011, is a good example of a credible initiative aimed to ban food waste from landfill sites by 2020 in the UK [10-12].

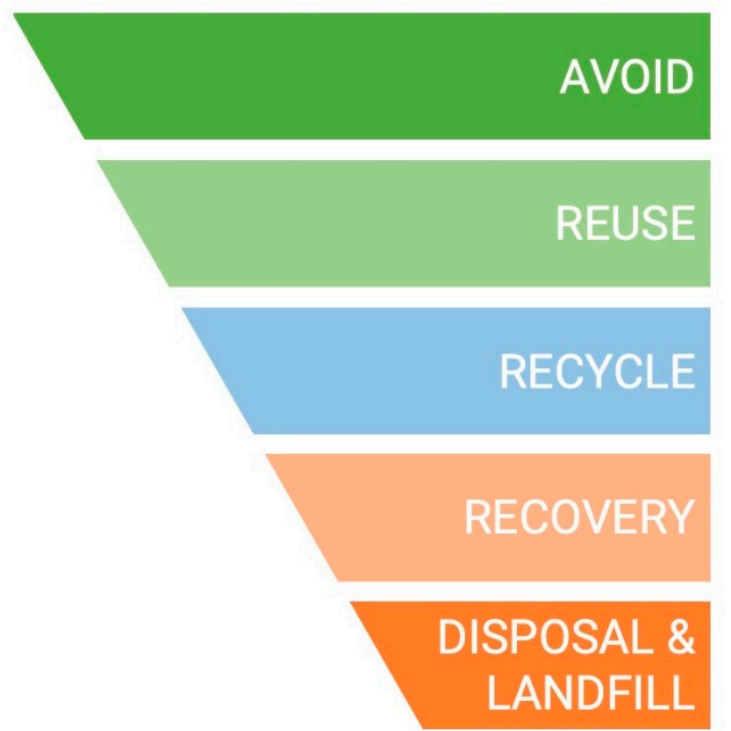

\section{Maximum conservation of resources}

\section{Reusing materials}

3. Recycling \& reprocessing materials

4. Energy recovery prior to disposal

\section{Zero conservation of resources}

Figure 1. Hierarchy for waste processing.

Besides their pollution and hazardous aspects, in many cases food wastes might have a potential as recycled raw materials, converting to high-added-value products, or they could be raw materials for other industries. Particularly, the recovery of food residues is receiving increased attention because of the growing awareness of the benefits deriving from potentially marketable components present in food wastes which represent a possible and usable resource to obtain useful products [12,13].

Two generations of food waste valorization strategies are distinguished: the first-generation is aimed to use the complete material streams for animal feed, energy or compost production (e.g., bioenergy production); the second-generation valorization rely on recovery and conversion of specific components in order to obtain various classes of products (e.g., chemicals, bioactives, biofuels, etc.). Interesting sources of plant-derived food wastes can be found in each one of the previously described categories (Table 1), from agricultural wastes until those derived by consumption (municipal waste), thus much of the efforts in waste processing have been focused on this topic. During industrial processing a wide range of materials is generated and, apart from wastes that industry has to eliminate by disposal centers, incineration, or landfill, they can be distinguished in byproducts and coproducts. According to Chemat et al. [14], "byproducts" are unintentional and unpredictable residual products that appear during the extraction process. They can be used directly or as ingredients to manufacture another finished product, generating a new economic value. "Coproducts" are materials, intentional and unavoidable, produced along with the main product and with the same importance. Coproducts must always meet specifications for their characteristics and may be used directly for a particular application [14]. Recent studies focused on the exploitation of food waste show many possibilities for food supply chain waste recovery such as the valorization of wastes into high-value chemicals. 
Table 1. Five system boundaries in the food supply chain (adapted from [9]).

\begin{tabular}{cc}
\hline & Vegetable Commodities and Products \\
\hline Agricultural Production & $\begin{array}{c}\text { Losses for mechanical damage and/or spillage during harvest operations, } \\
\text { crops separated postharvest, etc. }\end{array}$ \\
\hline Postharvest Handling and Storage & $\begin{array}{c}\text { Handling spillage and/or degradation, storage and transport during distribution } \\
\text { Processing }\end{array}$ \\
$\begin{array}{c}\text { Spillage and degradation during processing, separated crops not suitable to process } \\
\text { or during washing, peeling, boiling or accidental spillage }\end{array}$ \\
\hline Distribution & Market system \\
\hline Consumption & Household level \\
\hline
\end{tabular}

\subsection{Extend, Costs and Global Concern}

According to FAO, one-third of the edible parts of food produced for human consumption gets lost or wastes globally corresponding to 1.3 billion ton per year with a global cost of $\$ 750$ billion annually [9]. As previously described, food wastes and losses are produced throughout the whole food supply chain but dramatic differences between industrialized countries and developing countries are reported: low-income countries counted more than $40 \%$ of food losses during the postharvest and processing levels while, differently, in medium and high-income countries more than $40 \%$ of food waste is produced at the consumer level (222 million tons). This means that food is thrown away even if it is still suitable for human consumption. It must make us reflect that this amount is almost as high as the total net food production in sub-Saharan Africa which counts 230 million tons [9]. FAO estimated that the societal costs of food wastage amounted to about $\$ 2.6$ trillion in 2014: one trillion of them are costs from economic losses, $\$ 700$ billion are societal costs of environmental impact and $\$ 900$ billion are due to individual well-being losses [15].

Beside the mere economic loss, food wastes are responsible for dramatic Greenhouse Gases emissions (GHG) which, counting more than $8 \%$ of the total human GHG products, are almost as high as those derived by road transports. Climate changes and food wastes are closely related also in terms of water consumption, risks to biodiversity and soil erosions demonstrating the deep impact of this phenomenon on our society [16].

European amounts of food waste have been estimated for the year 2012 by Fusion's project "Estimates of European food waste levels" for the European Commission and published in 2016 (project supported by the European Community's Seventh Framework Programme under Agreement No. 311972) [8]. Thanks to a combination of national waste statistics and literature data collected within EU member States, it has been estimated the amount of food waste, including food and inedible parts associated with food. Resulting data confirmed the world estimations previously reported, evidencing household wastes as the most contributing sector to food waste (47 million tons), followed by processing (17 million tons). These numbers tell us that $72 \%$ of EU food waste comes from the aforementioned two sectors, while the remaining $28 \%$ is distributed among food service (11 million tons), production (nine million tons) and wholesale and retail (five million tons). World percentages of food losses and waste by production processes are reported in Table 2. In 2012, EU production of food wastes corresponded to $173 \mathrm{~kg}$ per capita (88 million tons whose costs amount approximately to 143 billion euros) and it has been estimated that these numbers could increase up to $30 \%$ by 2020 if no action is taken [8].

The Italian Parliament approved in 2016 a law against food waste (Law 166/2016 of 19 August 2016, n. 166) that has been considered the last step of the National Food Waste Prevention Plan [17] (Piano Nazionale di Prevenzione Degli Sprechi Alimentari (PINPAS)), with the aim of promoting the recovery and donation of food surpluses for charitable purposes and minimizing the negative impacts on the environment and on natural resources (reducing waste generation, encouraging reuse and recycle, extending products life). Italian food wastes have been counted around 5.1 million tons per year, and it has been expected that the new law will help to recover one million tons of food per year. This new Italian approach to food waste is just one step aimed to fight this evergreen and growing issue: 
to give an idea of the severity of the problem, one-quarter of the Italian forests serve just to absorb carbon dioxide emission produced as a result of the food waste production. Moreover, it has been calculated that if food waste was a Country, it would be the third-largest "emitter" of $\mathrm{CO}_{2}$ worldwide (just behind the USA and China) [18].

Table 2. Global food losses and food waste (adapted from [9]).

\begin{tabular}{cc}
\hline World Food Losses and Wastes (\%) by Manufacturing \\
\hline Cereals & 4.1 \\
Roots and tubers & 10.2 \\
Oil crops and pulses & 5.9 \\
Fruits and vegetables & 8.5 \\
Meat & 4.8 \\
Fish & 6.3 \\
Diary & 1.4 \\
\hline
\end{tabular}

\subsection{The EU Agenda against Food Wastes: The "Circular Economy Action Plan"}

The most relevant opportunity to rebalance the food supply chain at the European level and develop a sustainable, low carbon, resource-efficient and competitive economy, is represented by the so-called "circular economy". Shifting from "taking, making, consuming, throwing away" traditional linear scheme ("from cradle to grave") to a circular model which closes the loop ("from cradle to cradle"), is the main purpose of this action plan. The Juncker Commission of the European Parliament released a proposal for the circular economy in 2015, aimed to amend the already cited 2008 Waste Framework Directive. By maintaining products, materials and resources in the economy as far as possible, the circular economy will boost the EU's competitiveness in business, it will save energy and will reduce $\mathrm{CO}_{2}$ emissions. One key point stressed by the Commission to the European Parliament in 2015 refers to food waste as possible raw materials to be reused and injected back to the economy. For example, organic wastes could return back to the soil as sustainable fertilizers. Biomass and bio-based materials are other possible candidates as they can provide alternatives to fossil-based products and energy, and for this reason, the bio-based sector is supported by the EU with investments and projects through research funding. The Horizon 2020 work program 2016-2017 included the initiative "Industry 2020 in the circular economy" with funding for over $€ 650$ million for projects that supported the circular economy package [18]. In January 2017, a report on the implementation of the Circular Economy Action Plan was presented by the Commission to the EU Parliament confirming its full commitment. Strategies on plastic recycling and reuse, chemicals and wastes facilitation of management as well as dialogue with stakeholders are essential actions in order to make the circular economy a real growing and production system [19]. After intense debates among political groups, in March 2017 some relevant points have been prioritized: the need to give detailed definitions of "food waste", the need to reduce food waste up to $30 \%$ by 2025 and up to $50 \%$ by 2050 compared to the 2014 baseline, as well as the need to create an efficient monitoring system by 2017 [16]. Another report on the implementation of the Circular Economy Action Plan was published in March 2019 and some relevant key points have been stressed, among them building circular models of production giving importance to Circular Design and Production Processes (Ecodesign Working Plan 2016-2019); empowering consumers who will be able to make conscious choices based on reliable information; turning wastes into sources as secondary raw materials (revised waste legislative framework); proposing a new regulation for secondary raw material recover (Fertilizing Products regulation); building up strategies for plastic lifecycle [20].

All these points together with the already described actions, will accelerate the transition toward a greener, and climate-neutral economy [20]. Finally, all these considerations and actions are reported in the so-called Agenda 2030 [21], where the ecopharmacognostic approaches to biomolecules production 
totally fit with its goals, and where "sustainability" and "circularity of processes" are the key words for sustainable development in many industrial and social fields.

\section{Natural Products Research}

\subsection{The Role of Natural Products Research}

In the presence of a realistic threat against natural resources and biodiversity, there is a need to find green solutions to tackle food waste and meet the growing demand for bio-based products-for e.g., bio-based cosmetics, nutraceuticals, health products, etc.-and natural products research has a crucial role in developing more and more sustainable strategies. Pharmacognosy, defined as "the study of biologically active natural products", is a broad-based science with many applications from agricultural, to health and food industry. It is because of its multidisciplinary approach that it has become necessary to bring new theoretical and practical focuses on this science in order to direct scientists" practices in green terms. According to Cordell [22], "the challenge for researchers is how to best develop, innovate, and apply new strategies using knowledge in a sustainable manner, by considering and integrating the relevant cognate technologies and ideas". Using knowledge in a sustainable manner means also giving intellectual property rights protection to indigenous groups who hold important traditional medicinal lore, which is always an essential source of new crude drugs for pharmacognosy and the modern industry of herbals (botanicals) and bio-based products. In this direction goes the Nagoya Protocol of 2010 as one of the major events of the past 50 years which links traditional knowledge to genetic local and typical resources. It was out of these considerations, and many more that the term "ecopharmacognosy" was proposed by Cordell in 2015 [23] and defined as "the study of sustainable, biologically active, natural resources", in order to underline the need to bring biodiversity and knowledge to posterity. Besides many other aspects of research, working as an "ecopharmacognosist" means developing both new and established resources for nutraceuticals, cosmeceuticals as well as foods, fortified and functional foods included. Moreover, the industrial utilization of plant-based ingredients, directly handed down by popular and ethnobotanical knowledge, could contribute to developing a green bioeconomy in a global market which could have an annual trend of growth of $11 \%$, considering also that $10-25 \%$ of prescribed drugs nowadays contain at least one active compound isolated from plants [24].

\subsection{The Biorefinery Concept in Ecopharmacognosy: Recovery of Bioactive Compounds}

In addition to the aforementioned aspects of food waste management, other factors such as global warming, scarcity of resources and the constant lookout for natural compounds and products both from industries and markets, are driving the production chains to the possible use of food wastes as a source of biomaterials. Food wastes, since containing a variety of chemical components such as polysaccharides, proteins and lipids, have thousands of significant potential applications in the market as the research has demonstrated so far. The concept of "biorefinery" defined as "the sustainable processing of biomass into a spectrum of marketable products and energy" [25] refers, analogously to the petroleum refinery, to the conversion of raw material into commercially valuable products. The production of biofuels, bioplastics, nanoparticles and bioactive compounds are some of the most relevant industrial applications with valuable economic potential.

Plant biomass has been used for the production of biofuels for several decades, but recent developments permitted industrial organic wastes (carbohydrates from noodle wastes) as a possible source of bioethanol [26]. Another important example of biofuel production regards the conversion of cooking oil wastes into biodiesel by enzymatic transesterification $[27,28]$.

Bioactive compounds, naturally occurring as secondary metabolites in plants, exert physiological effects in living organisms. As they are already used as nutraceuticals, cosmetics and phytotherapeutic constituents, their recovery from food waste rather than from cultivated plants represents a sustainable production alternative. In addition, recovering the industrial food waste to obtain high-added-value 
molecules represents nowadays a significant economic potential for the industry. For example, the conversion of citrus peel residues into high-value products would allow companies to increase their competitiveness in the market. In fact, citrus fruits, including oranges (Citrus aurantium, Rutaceae), lemons (C. limon), limes (C. aurantiifolia), grapefruits (C. x paradisi) and tangerines (C. reticulata) are sources of soluble sugars, cellulose and hemicellulose, pectin and D-limonene. D-Limonene, mainly used in essential oils as flavor and fragrance compound, it can be obtained after distillation of peel residues and used as a building block to generate compounds with similar structures (e.g., carveol, carvone, a-terpineol, perrillyl alcohol and perillic acid) but with possible different biological activities and, therefore, with possible different industrial applications. Pectin, one of the most important food additives used as a gelling agent and thickener, is a complex structural heteropolysaccharide found also in citrus fruits (Citrus spp., Rutaceae) which contain 20-30\% extractable pectin. Moreover, many important flavonoids of industrial interest, including hesperidin, naringin and eriocitrin characterize the polyphenols profile of citrus peel and other solid residues of these species [12-29]. Another interesting example of industrial agri-food waste exploitation is grape pomace. In fact, after Citrus spp. production, Vitis sp. (Vitaceae), is the most produced crop in the world. Since grape pomace as food waste is approximately $20 \%$ of the weight of grapes processed, its valorization as a valuable byproduct has been the subject of numerous studies recently [30]. In fact, grape phenolics, such as flavonoids, anthocyanins, catechins, tannins and phenolic acids, are examples of extractable phytochemicals from grape pomace byproducts and they are known to have important health applications. Grape phenolics, from pomace and seeds, have been demonstrated to inhibit the oxidation of human low-density lipoproteins, neutralizing free radicals which are believed to contribute to the development of a number of health-related problems, like cardiovascular diseases and cancer [30]. Table 3 lists some more examples of industrial agri-foods residues which have been subjected to exploitation in the last 20 years. Furthermore, many more are available in literature data including valorization studies on animal-derived wastes such as fish and meat products to obtain proteins and saccharides [10]. Finally, the production of functional foods enriched in biologically active compounds is becoming increasingly popular in many countries and the potential markets are enormous.

Table 3. Examples of target phytochemicals from fruit and vegetable wastes.

\begin{tabular}{|c|c|c|c|}
\hline Extraction Method & Food Waste Biomass & Bioactives of Interest & References \\
\hline \multirow{7}{*}{ Ultrasound-assisted extraction (UAE) } & Coffee waste (Coffea arabica; C. canephora) & Phenolic compounds & [31] \\
\hline & Pomegranate waste (Punica granatum) & Carotenoids & [32] \\
\hline & Tomato waste (Solanum lycopersicum) & Pectins & [33] \\
\hline & Grapeseed (Vitis spp.) & Anthocyanins, Protantocianidins & [30] \\
\hline & Grape pomace & Flavonoids & [30] \\
\hline & Grape leaves & Phenolic compounds & [35] \\
\hline & Orange peel (Citrus spp.) & Phenolic compounds & [38] \\
\hline \multirow{4}{*}{ Microwave-assisted extraction (MAE) } & Tomato waste (S. lycopersicum) & Carotenoids & [39] \\
\hline & $\begin{array}{c}\text { Sea Buckthorn byproducts (Hippophae } \\
\text { rhamnoides) }\end{array}$ & Flavonoids & [40] \\
\hline & Agaricus bisporus L. byproducts & Erogosterol & [41] \\
\hline & Sage byproducts (Salvia officinalis) & Phenolic compounds & [42] \\
\hline \multirow{2}{*}{$\begin{array}{l}\text { Pressurized solvent extraction } \\
\text { (Naviglio }{ }^{\circledR} \text { extractor) }\end{array}$} & Vine-shoots (Vitis spp.) & $\begin{array}{l}\text { Phenolic, volatile, mineral } \\
\text { compounds }\end{array}$ & [46] \\
\hline & Grape pomace (Vitis spp.) & Polyphenols & [30] \\
\hline \multirow{5}{*}{ Supercritical fluids extraction (SFE) } & Hazelnut wastes (Corylus avellana) & Tryglycerides & [47] \\
\hline & Grape wastes (Vitis spp.) & Polyphenols and Fatty Acids & [48] \\
\hline & Wheat bran (Triticum aestivum) & Phenolic compounds and tocopherol & [49] \\
\hline & Sweet Potato (Ipomoea batatas) & Carotenoids & [50] \\
\hline & Tobacco waste (Nicotiana tabacum) & Solanesol & [51] \\
\hline
\end{tabular}


Table 3. Cont.

\begin{tabular}{|c|c|c|c|c|}
\hline \multicolumn{2}{|c|}{ Extraction Method } & Food Waste Biomass & Bioactives of Interest & References \\
\hline \multirow{5}{*}{\multicolumn{2}{|c|}{ Subcritical water extraction (SWE) }} & Rice bran (Oryza sativa) & Phenolic acids & [52] \\
\hline & & $\begin{array}{l}\text { Winery byproducts (Vitis spp.-from wine } \\
\text { supply chain production) }\end{array}$ & Catechins and proanthocyanidins & [53] \\
\hline & & Jackfruit peel waste (Arctocarpus heterophyllus) & Pectins & {$[56]$} \\
\hline & & Passion fruit peel (Passiflora edulis) & Oligosaccharides & [57] \\
\hline & & Grape skin (Vitis spp.) & Polyphenols & [58] \\
\hline \multirow{4}{*}{\multicolumn{2}{|c|}{ Deep eutectic solvents (DESs and NADES) }} & Olive pomace (Olea europaea) & Phenolic compounds & [61] \\
\hline & & Olive leaves (O. europaea) & Polyphenols & [62] \\
\hline & & Orange waste (Citrus spp.) & d-Limonene, Pectin and Hesperidin. & [63] \\
\hline & & Onion peel (A. cepa) & Polyphenols & [64] \\
\hline \multicolumn{2}{|c|}{ Enzyme-assisted extraction } & Tomato peels (S. lycopersicum) & Lycopene & [65] \\
\hline \multirow{14}{*}{$\begin{array}{l}\text { Hybrid } \\
\text { techniques }\end{array}$} & UAE- sohxlet & Oleaginous seeds & Fixed oils & [70] \\
\hline & UAE-SFE & Grape pomace (Vitis spp.) & Polyphenols & [71] \\
\hline & \multirow{5}{*}{ UAE- enzymatic } & Wheat bran (T. aestivum) & Arabinoxylans & [72] \\
\hline & & Citrus peel (Citrus spp.) & Pectins & [73] \\
\hline & & Tomato peel (S. lycopersicum) & Lycopene & [74] \\
\hline & & Olive waste (O. europaea) & Phenolic compounds & [75] \\
\hline & & \multicolumn{2}{|c|}{ Waste cooking oil } & [76] \\
\hline & \multirow{4}{*}{ UAE-NADESs } & Olive cake (O. europaea) & Phenolic compounds & [77] \\
\hline & & Onion seed $(A$. серa $)$ & Phenolic compounds & [77] \\
\hline & & Tomato byproducts (S. lycopersicum) & Phenolic compounds & [77] \\
\hline & & Pear canning byproducts (Pyrus communis) & Phenolic compounds & [77] \\
\hline & \multirow{3}{*}{ UAE-MAE } & Nitratia tangutorum Bobr. byproduct & Pectins & [82] \\
\hline & & Walnut green husk (Juglans regia) & Juglone & [83] \\
\hline & & Pomelo peel (Citrus maxima) & Pectins & {$[84,85]$} \\
\hline
\end{tabular}

\section{Emerging Technologies in Ecopharmacognosy: Green Extractions}

Going back to the concept of Cordell [22] regarding the meaning of ecopharmacognosy, it clearly emerges that research must necessarily consider the economic sustainability of its development toward the industrial valorization of waste/byproducts. In fact, beside its sustainable aspect, the recovery of high-value compounds must be economically profitable to be applied as an industrial production strategy. In light of all these considerations, conventional extraction processes are nowadays too expensive, time-consuming and unsustainable as they are quite laborious, requiring amounts of energy and organic solvents to be disposed of [86]. Therefore in the past years various green, safer, more efficient and often cheaper alternatives have been considered.

Following the green chemistry approach, which appeared for the first time in 1991, six leading principles for sustainable extractions were suggested by Chemat et al. [14], summarized below.

1. Innovation through selection and use of varieties of renewable plant sources;

2. Using alternative green solvents, mainly water or agri-solvents;

3. Reducing energy consumption by energy recovery and use of innovative technologies;

4. Favoring the production of coproducts instead of wastes in the bio- and agri-refining industries;

5. Reducing producing operations favoring short, safe, robust and controlled processes;

6. Aiming for obtaining non-denatured, biodegradable and contaminants-free extracts (i.e., without heavy metals, mycotoxins, etc.). 
EU environmental policy and legislation for the period 2010-2050 prioritized the use of eco-friendly solvents that need to be safe for workers, for the entire production chain process, for the environment and to be sustainably reused. To get more in-depth, in order to be considered green on the basis of the principles of green chemistry an eco-friendly solvent must meet 12 criteria [7], among which the main ones are listed below. An eco-friendly solvent must be:

- Coming from renewable feedstock;

- Recyclable with eco-efficient treatments;

- Exhibit similar solvating properties of commonly used solvents;

- Have a high boiling point and low vapor pressure;

- Be biodegradable under environmental conditions.

In 2013, Kerton and Mariotte [87] stated the following definition: "the greenest solvent, in terms of reducing wastes, is no solvent". Following their statement, it is necessary to mention the possibility of extracting molecules without the use of solvents (solvent-free extraction). The ancient cold pressing methods used in Italy for the extraction of fixed and essential oils from Mediterranean plants are the clearest example of these techniques. Nowadays we have the possibility to use more advanced technologies, such as extractions assisted by the use of ultrasounds or microwaves, which can be a valid tool to enhance the yield of biomolecules from agri-food wastes making their extraction easier. Some of the extraction techniques, with and without the use of green solvents or adjuvant technologies, which in recent decades have proven to have the most promising advantages from both an effectiveness and sustainability point of view, are described below.

\subsection{Ultrasound-Assisted Extraction (UAE)}

Ultrasound-assisted extraction has not only been used to extract bioactive compounds (e.g., polyphenolics, anthocyanins, aromatic compounds, polysaccharides and functional compounds such), but also essential oils, steroids, and lipids from plants. Ultrasound waves (from $20 \mathrm{kHz}$ to $10 \mathrm{MHz}$ ) have been successfully employed to extraction procedures using the cavitation effect. During the sonication process, longitudinal waves are created when a sonic wave meets a liquid medium, alternating compression and rarefaction waves. Sound waves create bubbles that grow and collapse. During the expansion cycle, these bubbles cause the expansion and diffusion of gas. During the compression cycle, the energy provided is not sufficient to retain the vapor phase in the bubble, so a rapid condensation occurs creating shock waves. These shock waves create microareas with very high temperature and pressure conditions, inducing the penetration of solvent by destroying the plant cell walls making easier the release of extractable compounds. During UAE extraction, several mechanisms of extraction have been identified and the results are the consequence of their combination: fragmentation, erosion, sonocapillarity effects, sonoporation, local shear stress and destruction of plant structures [88]. Moreover, ultrasound frequency can enhance the extraction yields with high reproducibility. Some other advantages derived by using ultrasounds as extraction strategies are low temperatures, reduction of extraction time, amount of energy and low $\mathrm{CO}_{2}$ emissions and, in addition, the UAE apparatus is cheaper than that of other innovative technologies. Moreover, UAE gives a crucial opportunity for a large commercial scale-up due to the availability of recently designed high-technology extraction units for large commercial operations [89].

\subsection{Microwave-Assisted Extraction (MAE)}

Microwave-assisted extraction works with electromagnetic radiations with a frequency ranging from 0.3 to $300 \mathrm{GHz}$ (generally $2.45 \mathrm{GHz}$ ). Microwaves, due to their electromagnetic nature, generate orthogonal electric and magnetic fields. The electric field causes the heating of extracting material through dipolar rotation and ionic conduction. The former is due to the alignment on the electric field in both the solvent and the solid sample of the molecules with a dipole moment: this oscillation produces collisions among the molecules producing thermal energy. Unlike classical conductive 
heating methods, microwaves heat the whole sample simultaneously and this is one of the main advantages. Another advantage of microwave heating is the disruption of weak hydrogen bonds promoted by the dipole rotation of the molecules. Moreover, higher viscosity of the medium lowers this mechanism by affecting molecular rotation while the migration of dissolved ions increases solvent penetration into the matrix facilitating the solvation of the sample. The latter consists of ionic currents induced in the solution by the electric field: frictions which occur after the medium resists these currents, causing heating liberation by a Joule effect. Size and charge of the ions in the solution strongly influence this phenomenon. The effect of microwave energy is also strongly dependent on the nature of both the solvent and the solid matrix. Finally, solvents used can be polar and nonpolar but the extracting selectivity and the ability of the medium to interact with microwaves can be modulated by using them in mixtures with different polarity properties [90].

\subsection{Pressurized Solvent Extraction (Naviglio ${ }^{\circledR}$ Extractor)}

Naviglio ${ }^{\circledR}$ Extractor has been presented as a technological innovation in the field of solid-liquid extractions as the result of the application of a new principle called "Naviglio's Principle" [91]. The device, proposed by D. Naviglio in 2003, is a rapid and dynamic solid-liquid extractor that applies the "Naviglio's principle" consisting "... in using a suitable solvent, generating a negative pressure gradient followed by a rapid equilibrium condition restoring, forcing the extraction of the not chemically bound compounds contained in the solid matrix ... " [91]. Naviglio ${ }^{\circledR}$ Extractor can operate at room- and lower-temperature, and it works by applying a pressure increase on the surface of the liquid phase containing the solid material (matrix) to be extracted. The device consists of an extracting chamber equipped with a cylinder and a piston where, at the bottom, one porous set lets the liquid phase and soluble substances pass through, while the solid particles are blocked. The solid raw material is put in the chamber that is filled with the solvent (organic, inorganic or a mixture). During the static phase, the pressure gradient is applied to allow the system to reach equilibrium at a pressure of about 8-9 atm. When the piston is moved from its equilibrium position, the dynamic phase starts: this step is performed five times and for a brief period of time with aim of remixing the solutions and allowing the diffusion of the extracted compounds. Hence, the movement of the piston alternatively produces static and dynamic steps until the extraction process is efficiently completed. Therefore, an extraction cycle is characterized by a static and a dynamic step and, by repeating more times these operations, a complete exhausting of the solid matrix can be obtained. Finally, the main advantages of Naviglio ${ }^{\circledR}$ Extractor are the use of low or room temperature that reduces the thermal stress for any heat susceptible substances present in the matrix, its ductility of use allowing an easy scale-up from laboratory research to industrial production according to demand (from bench until industrial apparatus) with large application possibilities (chemistry, medicine, agriculture, biology, etc.).

\subsection{Supercritical Fluids Extraction (SFE)}

Supercritical fluid extraction (SFE) is an extraction process based on the use of supercritical fluids as the extracting solvent from a matrix (for e.g., waste biomass). Extraction is usually from a solid matrix, but it can also be from liquid ones. Supercritical fluids are already well-established as alternative tools to extract both lipophilic and hydrophilic compounds from waste biomass. They possess liquid-like density and gas-like viscosity and these characteristics are the basis of the effectiveness of this extractive method. More than $90 \%$ of SFE has been performed using carbon dioxide $\left(\mathrm{CO}_{2}\right)$ - since it is considered as Generally Recognized As Safe (GRAS)—as a supercritical nonpolar solvent which solvating capacity is sometimes modified by polar cosolvents such as ethanol or methanol characterized by low critical constants (extraction conditions for supercritical $\mathrm{CO}_{2}$ are above the critical temperature of $31^{\circ} \mathrm{C}$ and critical pressure of $72 \mathrm{bar}$ ) [86]. Finally, the main green characteristics of this extraction process are (1) the opportunity to obtain "solvent-free" extracts and free of any solvent residue since the supercritical solvent turns into a gaseous state at room temperature; (2) the $\mathrm{CO}_{2}$ is nontoxic, nonflammable, odorless, tasteless, inert, and inexpensive; (3) various application possibilities in food, 
aromas, essential oils, cosmetics and nutraceutical industries. In fact, SFE can be used as a sample preparation step for analytical purposes or, on a larger scale, to either strip undesired material from raw material/waste biomass (for e.g., decaffeination from coffee seeds, polyphenols from exhausted coffee crude drug-Coffea arabica, C. canephora, Rubiaceae-, etc.) or collect fractions (for e.g., unsaponifiable fraction from oils, butters and waxes) and phytocomplexes (for e.g., terpene mixtures chemically analog to essential oils) [92].

\subsection{Subcritical Water Extraction (SWE)}

Among the more recent developments of green extraction, water at its subcritical state has been identified as an effective solvent with a number of advantages. At the temperature of $374{ }^{\circ} \mathrm{C}$ and a pressure of above 220 bar, water is considered at its supercritical state, but subcritical water extraction is performed between $100{ }^{\circ} \mathrm{C}$ and $374{ }^{\circ} \mathrm{C}$ and high pressure to keep the water liquid. By altering water conditions, this solvent changes its solvating properties which become unique and adaptable for an effective and environmentally friendly extraction. In fact, at these conditions, water decreases its polarity and becomes suitable for both polar and nonpolar compounds (this is due to a dramatic drop in the dielectric constant caused by the high temperature). As a low polar solvent, subcritical water allows us to obtain high extraction yields and reductions of extraction times. At the same time viscosity and density of water decrease too and thus enhance water penetration inside the sample matrix. Water is easily available, safe, low cost, nontoxic and noninflammable and environmentally friendly: all these advantages of use brought subcritical water extraction to receive much attention among researchers from various research fields. Furthermore, the equipment is easy to reproduce on a laboratory scale because of its technologically simple design [86-93].

\subsection{Natural Deep Eutectic Solvents (NADES)}

Firstly reported by Abbott in 2003 [94], deep eutectic solvents (DESs) are now recognized as new sustainable solvents. Because of their similarity with ionic liquids, some of their properties are the nonvolatility, the high viscosity and the nonflammability. The preparation of DESs is simple: it is sufficient to mix organic salts such as quaternary ammonium or phospohonium salt, with metal salts or hydrogen bond donors (able to create intramolecular hydrogen bonds between each other). NADESs (natural deep eutectic solvents) are DESs produced from primary metabolites commonly occurring in living cells (choline, sugars, carboxylic alcohol, etc.) which are involved in the biosynthesis and storage of various nonpolar compounds. They can be defined as green solvents because of their following properties: they have a low cost, they are simple to prepare, nontoxic, biodegradable, readily available and they can be tuned easily for specific applications. NADESs capacity to be good extractive solvents depends on their combination and physiochemical properties. Water can also be added to modify polarity. Finally, it has been estimated that 108 are the possible combinations of NADESs and their cost is comparable to one of the conventional solvents. However, some disadvantages need also to be described: they are difficult to reuse or recover; the industrial scale-up is possible only when the extract is used without purification steps, high energy consumption could be required for stirring the extraction system (solvent (s) and matrix/waste biomass) because of the high viscosity of NADESs [86-95]. New forms of NADESs have been recently described as therapeutic deep eutectic solvents (THEDESs) by Aroso et al. [96] as bioactive eutectic mixtures which contain an active pharmaceutical ingredient as one of the constituents of the mixture.

\subsection{Enzyme-Assisted Extraction}

Enzyme-assisted extraction (EAE) has gained much attention nowadays because of the need for green extraction technologies. Even if the use of enzymes to extract bioactive compounds is already well-established, its association with other technologies such as sonication and microwaves, is a promising tool. Enzymes, with their ability to disrupt cell walls, represent a good alternative to release compounds in the solution with higher yields compared to other conventional extraction methods. 
In particular, the use of enzymes in extraction procedures enables to reduce solvent amounts and also to extract compounds which are naturally found in a bound form with other plant structural components. Among the advantages of using enzyme-assisted extraction, there are low extraction time, high yields and low energy and low solvent consumption. Cellulases, pectinases and hemicellulases are often required to hydrolyze cell wall components and thus increase cell wall permeability. They can be derived from bacteria, fungi, animal organs or plant extracts. Appropriate operational conditions and enzymes combination are important parameters to obtain a successful result. Enzymatic extractions are subjected to continuous research: good examples are the extraction of oils, polyphenols, phenolic acids, vanillin, polysaccharides and lycopene from tomatoes (Solanum lycopersicum, Solanaceae) [97]. The release of bound polyphenols from plant cell walls represents a never-ending challenge among researchers that need to find green alternatives to the commonly used acid and alkaline hydrolysis conditions. Enzymes, such as feruloyl esterase, can be involved in the release of bound phenolics, in particular, phenolic acid from cereal pericarps: ferulic acid exhibited numbers of possible applications such as in health, medicine, food and cosmetic fields [98].

\subsection{Hybrid Techniques}

Beside all the innovative and sustainable extraction strategies described above, the possibility of combining two or more of them, in order to optimize results, is receiving great attention nowadays. Various combinations of extraction procedures have been investigated so far on plant materials. In particular, the combination of ultrasounds with conventional or unconventional methods has demonstrated to be effective. Ultrasound-assisted Soxhlet extraction (Sono-Soxhlet) combines the advantages of the Soxhlet extraction (availability of fresh solvent) and of ultrasounds by enhancing mass transfer and reduction of extraction time. This system has been used for the extraction of lipids from seeds, sausage products, cheese and bakery products. Another promising hybrid technique, which is fast and efficient, is made by the combination of ultrasound-assisted extraction (UAE) and microwave-assisted extraction (MAE). This combination allows us to dramatically shorten extraction time with potential great industrial applications. The mechanical ultrasonic effect promotes the release of soluble compounds from the plant matrices by disrupting cell walls while microwaves heat the sample inducing the quick migration of molecules. The simultaneous irradiation increases the penetration of the solvent into the plant matrix and can increase the solubility of compounds. This technique has been used for the extraction of pectin from pomelo peel (Citrus maxima, Rutaceae) [84]. Sonication has also demonstrated a positive effect when coupled with supercritical fluids $\left(\mathrm{SC}-\mathrm{CO}_{2}\right)$ since UAE enhances the mass transfer of ginger to the solvent used for extraction of pungent compounds increasing the yields [99]. Among many other possible combinations of technologies that can be used to extract biomolecules following the green chemistry concepts, two other strategies need to be mentioned: Ultrasound-Assisted chemical hydrolysis and Ultrasound-Assisted enzymatic hydrolysis. Since the extraction technique's choice of the desired metabolite has to be a result of a compromise between the efficiency and reproducibility of extraction, the use of ultrasounds (alone or in combination with other techniques) has become nowadays, one of the most effective devices used to obtain green extracts because of the ease procedures and considerations of cost, time, safety and degree of automation [88].

\section{Bound Phenolics from Waste Biomass: A Case Study}

In various plant materials, phenolic compounds are commonly found in a bound form. Bound phenolics comprise, on average, $24 \%$ of the total phenolics in food, with peaks of $88 \%$ of total phenolic molecules in brown rice [100]. Acosta-Estrada [101] resumed several studies reporting food sources with nonextractable phenolics' percentages (Table 4): these molecules are gaining attention as a considerable amount of them is often not detected due to the limitations of conventional extraction methods. The possibility of extracting bound molecules, otherwise difficult to identify, can be particularly advantageous in case of waste biomass recovery which, as a result of the industrial processing, are often apparently exhausted. 
Table 4. Insoluble bound phenolic (data from [101]).

\begin{tabular}{ccc}
\hline \multicolumn{3}{c}{ Bound Phenolics in Food Sources } \\
\hline Source & Species & Insoluble Bound Phenolics in Total Phenolic \% \\
\hline Apple & Malus domestica & 6.50 \\
Banana & Musa acuminate & 33.10 \\
Cranberry pomace & Vaccinium macrocarpon & 76.27 \\
Orange & Citrus sinensis & 24.30 \\
Carrot & Daucus carota & 37.6 \\
Onion & Allium cepa & 9.70 \\
Potato & Solanum tubersum & 39.9 \\
Barley & Hordeum vulgare & 70.08 \\
Maize & Zea mays & 85.00 \\
Rice & Oryza sativa & 62 \\
Brown rice & Oryza sativa & 88 \\
Wheat & Triticum spp. & 75 \\
\hline
\end{tabular}

Bound phenolic acids, as well as other potential health-promoting substances, are found covalently linked to cell wall structural components such as hemicelluloses (arabinoxylans), celluloses, lignins, pectins and proteins, and often remain in the extraction's residue which is normally discarded and unutilized. These strong bonds provide physical and chemical barriers, protection for the plant against pathogens as well as from free radicals. Ferulic acid, for example, is attached with ester linkages to the arabinoxylans of the cell wall and form ether linkages with lignin at the outermost part of the cereal caryopsis. Moreover, ferulic acid oligomers form polysaccharide-polysaccharide cross-linkages, limiting the biodegradability of the cell walls [102].

Agri-industrial byproducts, such as those coming from cereals and vegetables supply chains, are good sources of lignocellulosic materials rich in bound phenolics.

As recently reviewed by Wang et al. [103], there are many possibilities for the extraction of bound phenolics, using both chemical, enzymatic and physical treatments. However, the commonly used alkaline or acid hydrolysis have demonstrated some negative aspects such as the long extraction time and partial solubilization of the molecules. By contrast, the use of mechanical extraction methods (Ultrasound-Assisted Extraction (UAE), Microwave Assisted Extraction (MAE), etc.) has demonstrated to reduce extraction times and improve the release of bound phenolic molecules.

Recently, hybrid extraction techniques have been successfully used to extract bound phenolics from plant byproducts obtaining more interesting results than those obtained with commonly used extraction techniques. Coupling sonication to alkaline hydrolysis, in fact, allows shortening extraction times enhances the phenolic yields when compared to conventional hydrolysis conditions $[80,81]$ and enzymatic treatments [72]. Gonzales et al. [80] used Ultrasound-Assisted alkaline hydrolysis to extract bound phenolics from cauliflower (Brassica oleracea) wastes, one of the most consumed vegetables of the Brassicaceae family, by comparing the obtained results about extractable and nonextractable phenolic amounts. This study demonstrated that a significant amount of phenolic molecules has been underestimated before, and that cauliflower wastes have an interesting potential as a source of bioactive molecules. Ultrasonication improves the phenolic extraction by damaging the plant matrix, which, once broken, increases the surface interaction area between solvent (s) and the plant matrix to be extracted. This effect allowed the sodium hydroxide to penetrate more efficiently in the plant matrix to break ester linkages and enhance the release of the molecules. Therefore, combining sonication and alkaline hydrolysis demonstrated to be effective in the release of a higher quantity of phenolics. The effect of ultrasonication on the release of bound phenolic molecules has been also evaluated on other plant sources, such as maize germs [81]. Following the guidelines of the European Commission, maize byproducts have been investigated for their total phenolic content and antioxidant activity comparing various extraction techniques. The large amounts of Zea mays L. productions made in this plant an interesting and promising source of bioactives that could be valorized and reintroduced 
in the market as high-added-value products. Using a similar hybrid extraction method as the one previously described, maize germs exhibited a higher amount of phenolic acids and total phenolic compounds compared to the results obtained with other commonly used techniques. Moreover, by combining alkaline hydrolysis with sonication, an increase of antioxidant activity of the bound phenolic extract occurred. The results of this study confirmed the effective applicability of the previously described hydrolysis method on maize germ, which allowed to obtain enriched extracts by associating ultrasounds with alkaline hydrolysis despite the reduction of extraction times. Another interesting research, published in 2018 by Đurović et al. [103], demonstrated a positive effect of combining green extraction methods to commonly used technologies, on the release of bound phenolics from yellow soybean (Glycine max) seeds. In particular, combining microwave-assisted extraction and alkaline and acid hydrolysis, appeared to enhance the release of bound phenolic acids from the plant matrix as well as extraction yields and antioxidant activity. Finally, the use of enzymes could also be a good alternative to chemical hydrolysis since they are, in some cases, more effective and specific. Associating an enzymatic pretreatment with the extraction process can, therefore, help in the targeted extraction of phenolic molecules from plant sources and byproducts as demonstrated by Balasubramaniam [104]. The phenolic yield extracted from finger millet (Eleusine coracana), increased more than two-fold using enzymatic treatment followed by sonication compared to the commonly used method, while the yield obtained only by sonication has remained unchanged.

\section{Conclusions: Up-Scaling and Perspectives}

Green extractions, that is hybrid techniques involving the coupling of two or more extractive techniques, make it possible to improve food waste processing methods in a sustainable and more environmentally friendly way. Hybrid techniques, some of which are summarized in this review, allow industries to minimize processing and recovery times for waste materials, thus reducing working costs, energy consumption and, at the same time, increasing the extraction efficiency and quality of the products obtained. Food waste from agri-food supply chains can thus become raw materials with high-value-added and economic potential, and be reintroduced into the market through the circular economy, as suggested by the European Commission [3]. Bound phenolic molecules, previously underrated, have been attracting increasing attention in recent years because they characterize most of the waste biomass of the agricultural industry, especially cereals, and have shown great potential applications in health, nutraceutical and cosmetic fields. For these reasons, applying the most innovative and green techniques for their extraction is of particular interest nowadays. Some of the publications presented in the present review have considered the importance of scale-up of their research, proposing innovative industrial plants such as an ultrasound-microwave extractor by Đurović et al. [105]. Other studies are necessary for a careful cost-benefit analysis that will certainly be the subject of research in the short term. The lack of information on scale-up and the high investment associated with emergent extraction processes underline the initial prejudice of the industry to these new extracting technologies. However, some recent publications [106] presented rapid methods to estimate the cost of the manufacturing of extracts obtained by green extractions, especially using sonication and supercritical fluids, contributing to the possibility of increasing the application of these extractions at industrial level. Pending further research in this field, it can certainly be concluded that, given the countless risks to the environment, health and climate that the planet is experiencing in recent years, a drastic change of perspective in the field of applicative research is needed. As Cordell proposed [22,23], in fact, research has the responsibility to propose increasingly sustainable and environmentally friendly solutions for the industry to make industrial processes increasingly greener.

Author Contributions: All authors contributed equally to this work. All authors have read and agreed to the published version of the manuscript.

Funding: This work was supported by the Emilia Romagna region within the "POR-FSE 2014-2020—Obiettivo 10 " research projects financial program. 
Acknowledgments: Thanks goes to Immacolata Maresca and Alessandro Grandini for technical support and assistance.

Conflicts of Interest: The authors declare no conflict of interest.

\section{References}

1. Clemént, G. Giardini, Paesaggio e Genio Naturale, 1st ed.; Quodlibet srl: Macerata, Italy, 2013; pp. $19-21$.

2. Stahel, W.R.; Reday-Mulvey, G. Jobs for tomorrow: The potential for substituting manpower for energy. In Circular Economy and Sustainability_Two Faces of the Same Coin; Vantage Press: New York, NY, USA, 1981; Volume 116.

3. European Commission. Report from the Commission to the European Parliament, the Council, the European Economic and social Committee and the Committee of the Regions. In Closing the Loop-An EU Action Plan for the Circular Economy; European Commission: Brussels, Belgium, 2015.

4. Saavedra, Y.M.B.; Iritani, D.R.; Pavan, A.L.R.; Ometto, A.R. Theoretical contribution of industrial ecology to circular economy. J. Clean. Prod. 2018, 170, 1514-1522. [CrossRef]

5. Zitkowski, H.E. The Recovery of Potash from Beet-Sugar House Waste Liquors. J. Ind. Eng. Chem. 1917, 9, 692-694. [CrossRef]

6. Pruthi, J.S.; Parekh, C.M.; Girdhari, L. An integrated process for the recovery of essential oil and pectin from mandarin orange waste. J. Food Sci. 1961, 10, 372-378.

7. Chemat, F.; Vian, M.A.; Ravi, H.K.; Khadhraoui, B.; Hilali, S.; Perino, S.; Tixier, A.-S.F. Review of Alternative Solvents for Green Extraction of Food and Natural Products: Panorama, Principles, Applications and Prospects. Molecules 2019, 24, 3007. [CrossRef]

8. Stenmarck, Å.; Jensen, C.; Quested, T. Fusions: Estimates of European Food Waste Levels; Fusions-IVL Swedish Environmental Research Institute: Stockholm, Sweden, 2016.

9. FAO (Food and Agricultural Organization of the United Nations). Global Food Losses and Food Waste-Extend, Causes and Prevention; FAO: Düsseldorf, Germany, 2011.

10. Ravindran, R.; Jaiswal, A.K. Exploitation of Food Industry Waste for High-Value Products. Trends Biotechnol. 2016, 34, 58-69. [CrossRef]

11. Vision 2020. Achieving Zero Waste to Landfill. Available online: Www.vision2020.info (accessed on 28 January 2020).

12. Ki Lin, C.S.; Pfaltzgraff, L.A.; Herrero-Davila, L.; Mubofu, E.B.; Abderrahim, S.; Clark, J.K.; Koutinas, A.A.; Kopsahelis, N.; Stamatelatou, N.; Dickson, F.; et al. Food waste as a valuable resource for the production of chemicals, materials and fuels. Current situation and global perspective. Energy Environ. Sci. 2016, 6, 426-464. [CrossRef]

13. Laufenberg, G.; Kunz, B.; Nystroem, M. Transformation of vegetable waste into value added products: (A) the upgrading concept; (B) practical implementations. Bioresour. Technol. 2003, 87, 167-198. [CrossRef]

14. Chemat, F.; Abert Vian, M.; Cravotto, G. Green Extraction of Natural Products: Concept and Principles. Int. J. Mol. Sci. 2012, 13, 8615-8627. [CrossRef]

15. FAO (Food and Agricultural Organization of the United Nations). Food Wastage Foodprint-Full-Cost Accounting 79; FAO: Düsseldorf, Germany, 2014.

16. Fattibene, D.; Bianchi, M. Fighting against Food Losses and Waste: An EU Agenda; IAI Working Papers 17; IAI: Rome, Italy, 2017.

17. Ministero dell'Ambiente e della Tutela del Territorio e del Mare. Available online: https://www.minambiente.it/ comunicati/litalia-avra-un-piano-nazionale-di-prevenzione-dello-spreco-alimentare (accessed on 16 July 2019).

18. FAO (Food and Agricultural Organization of the United Nations). Food Wastage Footprint. Impacts on Natural Resources; Summary Report; FAO: Düsseldorf, Germany, 2013.

19. European Commission. Report from the Commission to the European Parliament, the Council, the European Economic and social Committee and the Committee of the Regions. In On Implementation to the Circular Economy Action Plan; European Commission: Brussels, Belgium, 2017.

20. European Commission. Report from the Commission to the European Parliament, the Council, the European Economic and social Committee and the Committee of the Regions. In On implementation to the Circular Economy Action Plan; European Commission: Brussels, Belgium, 2019. 
21. European Commission. Available online: https:/ec.europa.eu/international-partnerships/news/europeanunion-presents-its-progress-towards-sustainable-development_en (accessed on 18 December 2019).

22. Cordell, G.A. Cognate and cognitive ecopharmacognosy-in an anthropogenic era. Phytochem. Lett. 2017, 20, 540-549. [CrossRef]

23. Cordell, G.A. Ecopharmacognosy and the responsibilities of natural product research to sustainability. Phytochem. Lett. 2015, 11, 332-346. [CrossRef]

24. Devappa, R.K.; Rakshit, S.K.; Dekker, R.F.H. Forest biorefinery: Potential of poplar phytochemicals as value-added co-products. Biotechnol. Adv. 2015, 33, 681-716. [CrossRef] [PubMed]

25. Shim, Y.Y.; Emami, S.; Ratanapariyanuch, K.; Reaney, M.J.T. Biorefinery of Plant-Based Products. In Plant Bioproducts; Chen, G., Weselake, R., Singer, S., Eds.; Springer: New York, NY, USA, 2018; pp. 201-218.

26. Yang, X.; Lee, S.J.; Yoo, H.Y.; Choi, H.S.; Park, C.; Kim, S.W. Biorefinery of instant noodle waste to biofuels. Bioresour. Technol. 2014, 159, 17-23. [CrossRef] [PubMed]

27. Seong, P.J.; Jeon, B.W.; Lee, M.; Cho, D.H.; Kim, D.K.; Jung, K.S.; Kim, S.W.; Han, S.O.; Kim, Y.H.; Park, C. Enzymatic coproduction of biodiesel and glycerol carbonate from soybean oil and dimethyl carbonate. Enzym. Microb. Technol. 2011, 48, 505-509. [CrossRef]

28. Lee, M.; Lee, D.; Cho, J.; Park, C. Enzymatic Biodiesel Synthesis in Semi-Pilot Continuous Process in Near-Critical Carbon Dioxide. Appl. Biochem. Biotechnol. 2013, 171, 1118-1127. [CrossRef]

29. Rafiq, S.; Kaul, R.; Sofi, S.A.; Bashir, N.; Nazir, F.; Ahmad Nayik, G. Citrus peel as a source of functional ingredient: A review. J. Saudi Soc. 2018, 17, 351-358. [CrossRef]

30. Tacchini, M.; Burlini, I.; Bernardi, T.; De Risi, C.; Massi, A.; Guerrini, A.; Sacchetti, G. Chemical characterisation, antioxidant and antimicrobial screening for the revaluation of wine supply chain by-products oriented to circular economy. Plant Biosyst. 2018, 153, 809-816. [CrossRef]

31. Al-Dhabi, N.A.; Ponmurugan, K.; Maran Jeganathan, P. Development and validation of ultrasound-assisted solid-liquid extraction of phenolic compounds from waste spent coffee grounds. Ultrason. Sonochem. 2017, 34, 206-213. [CrossRef]

32. Goula, A.M.; Ververi, M.; Adamopoulou, A.; Kaderides, K. Green ultrasound-assisted extraction of carotenoids from pomegranate wastes using vegetable oils. Ultrason. Sonochem. 2017, 34, 821-830. [CrossRef]

33. Grassino, A.N.; Brnčić, M.; Vikić-Topić, D.; Roca, S.; Dent, M.; Brnčić, S.R. Ultrasound assisted extraction and characterization of pectin from tomato waste. Food Chem. 2016, 198, 93-100. [CrossRef]

34. Hromadkova, Z.; Ebringerova, A. Ultrasonic extraction of plant materials-Investigation of hemicellulose release from buckwheat hulls. Ultrason. Sonochem. 2003, 10, 127-133. [CrossRef]

35. Caili, F.; Haijun, T.; Quanhong, L.; Tongyi, C.; Wenjuan, D. Ultrasound-assisted extraction of xyloglucan from apple pomace. Ultrason. Sonochem. 2006, 13, 511-516.

36. Rabelo, R.S.; Machado, M.T.C.; Martínez, J.; Hubinger, M.D. Ultrasound assisted extraction and nanofiltration of phenolic compounds from artichoke solid wastes. J. Food Eng. 2016, 178, 170-180. [CrossRef]

37. da Silva Lima, R.; Nunes, I.L.; Block, J.M. Ultrasound-Assisted Extraction for the Recovery of Carotenoids from Guava's Pulp and Waste Powders. Plant Foods Hum. Nutr. 2020, 75, 63-69. [CrossRef] [PubMed]

38. Ghasempour, N.; Elhami Rad, A.H.; Javanmard, M.; Azarpazhouh, E.; Armin, M. Optimization of conditions of ultrasound-assisted extraction of phenolic compounds from orange pomace (Citrus sinensis). Int. J. Biol. Chem. 2020, 12, 10-19. [CrossRef]

39. Tacchini, M.; Burlini, I.; Maresca, I.; Grandini, A.; Bernardi, T.; Guerrini, A.; Lerin, L.; Sacchetti, G. Polyphenols from Vitis vinifera Lambrusco By-Products (Leaves from Pruning): Extraction Parameters Evaluation Through Design of Experiment. Nat. Prod. Commun. 2019, 14, 1-7. [CrossRef]

40. Strati, I.F.; Oreopoulou, V. Recovery of carotenoids from tomato processing by-products-A review. Food Res. Int. 2014, 65, 311-321. [CrossRef]

41. Périno-Issartier, S.; Huma, Z.-e.; Abert-Vian, M.; Chemat, F. Solvent Free Microwave-Assisted Extraction of Antioxidants from Sea Buckthorn (Hippophae rhamnoides) Food by-Products. Food Bioprocess Technol. 2010, 4, 1020-1028. [CrossRef]

42. Heleno, S.A.; Prieto, M.A.; Barros, L.; Rodrigues, A.; Barreiro, M.F.; Ferreira, I.C.F.R. Optimization of microwave-assisted extraction of ergosterol from Agaricus bisporus L. by-products using response surface methodology. Food Bioprod. Process. 2016, 100, 25-35. [CrossRef] 
43. Zeković, Z.; Pintać, D.; Majkić, T.; Vidović, S.; Mimica-Dukić, N.; Teslić, N.; Pavlić, B. Utilization of sage by-products as raw material for antioxidants recovery-Ultrasound versus microwave-assisted extraction. Ind. Crop. Prod. 2017, 99, 49-59. [CrossRef]

44. Ferreira, S.S.; Passos, C.P.; Cardoso, S.M.; Wessel, D.F.; Coimbra, M.A. Microwave assisted dehydration of broccoli by-products and simultaneous extraction of bioactive compounds. Food Chem. 2018, 246, 386-393. [CrossRef]

45. Prakash Maran, J.; Sivakumar, V.; Thirugnanasambandham, K.; Sridhar, R. Microwave assisted extraction of pectin from waste Citrullus lanatus fruit rinds. Carbohydr. Polym. 2014, 101, 786-791. [CrossRef] [PubMed]

46. Naviglio, D.; Pizzolongo, F.; Ferrara, L.; Naviglio, B.; Aragòn, A.; Santini, A. Extraction of pure lycopene from industrial tomato waste in water using the extractor Naviglio ${ }^{\circledR}$. Afr. J. Food Sci. 2008, 2, 37-44.

47. Manna, L.; Bugnone, C.A.; Banchero, M. Valorization of hazelnut, coffee and grape wastes through supercritical fluid extraction of triglycerides and polyphenols. J. Supercrit. Fluids 2015, 104, $204-211$. [CrossRef]

48. Aizpurua-Olaizola, O.; Ormazabal, M.; Vallejo, A.; Olivares, M.; Navarro, P.; Etxebarria, N.; Usobiaga, A. Optimization of Supercritical Fluid Consecutive Extractions of Fatty Acids and Polyphenols from Vitis Vinifera Grape Wastes. J. Food Sci. 2015, 80, E101-E107. [CrossRef] [PubMed]

49. Kwon, K.T.; Uddin, M.d.S.; Jung, G.-W.; Sim, J.E.; Chun, B.S. Supercritical Carbon Dioxide Extraction of Phenolics and Tocopherols Enriched Oil from Wheat Bran. Int. J. Nutr. Food Eng. 2010, 4, 188-193.

50. de Andrade Lima, M.; Kestekoglou, I.; Charalampopoulos, D.; Chatzifragkou, A. Supercritical Fluid Extraction of Carotenoids from Vegetable Waste Matrices. Molecules 2019, 24, 466. [CrossRef]

51. Wang, Y.; Gu, W. Study on supercritical fluid extraction of solanesol from industrial tobacco waste. J. Supercrit. Fluids 2018, 138, 228-237. [CrossRef]

52. Fabian, C.; Tran-Thi, N.Y.; Kasim, N.S.; Ju, Y.-H. Release of phenolic acids from defatted rice bran by subcritical water treatment. J. Sci. Food Agric. 2010, 90, 2576-2581. [CrossRef]

53. García-Marino, M.; Rivas-Gonzalo, J.C.; Ibáñez, E.; García-Moreno, C. Recovery of catechins and proanthocyanidins from winery by-products using subcritical water extraction. Anal. Chim. Acta 2006, 563, 44-50. [CrossRef]

54. Munir, M.T.; Kheirkhah, H.; Baroutian, S.; Quek, S.Y.; Young, B.R. Subcritical water extraction of bioactive compounds from waste onion skin. J. Clean. Prod. 2018, 183, 487-494. [CrossRef]

55. Kim, S.-W.; Ko, M.-J.; Chung, M.-S. Extraction of the flavonol quercetin from onion waste by combined treatment with intense pulsed light and subcritical water extraction. J. Clean. Prod. 2019, 231, 1192-1199. [CrossRef]

56. Li, W.; Fan, Z.; Wu, Y.; Jiang, Z.; Shi, R. Eco-friendly extraction and physicochemical properties of pectin from jackfruit peel waste by subcritical water. J. Sci. Food Agric. 2019, 7, 5027-5033. [CrossRef] [PubMed]

57. Klinchongkon, K.; Khuwijitjaru, P.; Wiboonsirikul, J.; Adachi, S. Extraction of Oligosaccharides from Passion Fruit Peel by Subcritical Water Treatment. J. Food Process. Eng. 2015, 40, e12269. [CrossRef]

58. Duba, K.S.; Casazza, A.A.; Mohamed, H.B.; Perego, P.; Fiori, L. Extraction of polyphenols from grape skins and defatted grape seeds using subcritical water: Experiments and modeling. Food Bioprod. Process. 2015, 94, 29-38. [CrossRef]

59. Xia, H.; Matharu, A.S. Unavoidable food supply chain waste: Acid-free pectin extraction from mango peel via subcritical water. Faraday Discuss. 2017, 202, 31-42. [CrossRef]

60. Bosiljkov, T.; Dujmić, F.; Cvjetko Bubalo, M.; Hribar, J.; Vidrih, R.; Brnčić, M.; Zlatic, E.; Radojčić, I.; Ković, R.; Jokić, S. Natural deep eutectic solvents and ultrasound-assisted extraction: Green approaches for extraction of wine lees anthocyanins. Food Bioprod. Process. 2017, 102, 195-203. [CrossRef]

61. Chanioti, S.; Tzia, C. Extraction of phenolic compounds from olive pomace by using natural deep eutectic solvents and innovative extraction techniques. Innov. Food Sci. Emerg. Technol. 2018, 48, 228-239. [CrossRef]

62. Athanasiadis, V.; Grigorakis, S.; Lalas, S.; Makris, D.P. Methyl $\beta$-cyclodextrin as a booster for the extraction for Olea europaea leaf polyphenols with a bio-based deep eutectic solvent. Biomass Convers. Biorefinery 2017, 8, 345-355. [CrossRef]

63. Bogaars, R.A. Exploring Commercial Applications of Natural Deep Eutectic Solvents. Master's Thesis, TU Delft, Delft, The Netherlands, 2015; p. 78.

64. Pal, C.B.T.; Jadeja, G.C. Deep Eutectic Solvents-based Extraction of Polyphenolic Antioxidants from Onion (Allium cepa L.) Peel. J. Sci. Food Agric. 2018, 99, 1969-1979. [CrossRef] 
65. Papaioannou, E.H.; Karabelas, A.J. Licopene recovery from tomato peel under mild conditions assisted by enzymatic pre-treatment and non-ionic surfactants. Acta Biochim. Pol. 2012, 59, 71-74. [CrossRef]

66. Laroze, L.; Soto, C.; Zúñiga, M.E. Phenolic antioxidants extraction from raspberry wastes assisted by-enzymes. Electron. J. Biotechnol. 2010, 13, 11-12. [CrossRef]

67. Faulds, C.B.; Sancho, A.I.; Bartolomè, B. Mono- and dimeric ferulic acid release from brewer's spent grain by fungal feruloyl esterases. Appl. Microbiol. Biotechnol. 2002, 60, 489-494. [PubMed]

68. Yu, P.; Maenz, D.D.; McKinnon, J.J.; Racz, V.J.; Christensen, D.A. Release of Ferulic Acid from Oat Hulls by Aspergillus Ferulic Acid Esterase and Trichoderma Xylanase. J. Agric. Food Chem. 2002, 50, 1625-1630. [CrossRef] [PubMed]

69. Tam, M.T.; Duy, N.Q.; Minh, N.P.; Dao, D.T.A. Optimization of beta-glucans extraction from waste brewer's yeast saccharomyces cerevisiae using autolysis, enzyme, ultrasonic and combined enzyme-ultrasonic treatment. Am. J. Res. Commun. 2013, 1, 149-158.

70. Luque-Garcia, J.L.; Luque de Castro, M.D. Ultrasound-assisted soxhlet extraction: An expeditive approach for solid sample treatment: Application to the extraction of total fat from oleaginous seeds. J. Chromatogr. A 2004, 1034, 237-242. [CrossRef] [PubMed]

71. Da Porto, C.; Natolino, A.; Decorti, D. The combined extraction of polyphenols from grape marc: Ultrasound assisted extraction followed by supercritical $\mathrm{CO}_{2}$ extraction of ultrasound-raffinate. LWT -Food Sci. Technol. 2015, 61, 98-104. [CrossRef]

72. Wang, J.; Sun, B.; Liu, Y.; Zhang, H. Optimisation of ultrasound-assisted enzymatic extraction of arabinoxylan from wheat bran. Food Chem. 2014, 150, 482-488. [CrossRef]

73. Ma, X.; Zhang, L.; Wang, W.; Zou, M.; Ding, T.; Ye, X.; Liu, D. Synergistic effect and Mechanism of combining ultrasound and pectinase on pectin hydrolysis. Food Bioprocess Technol. 2016, 9, 1249-1257. [CrossRef]

74. Ladole, M.R.; Nair, R.R.; Bhutada, Y.D.; Amritkar, V.D.; Pandit, A.B. Synergistic effect of ultrasonication and co-immobilized enzymes on tomato peels for lycopene extraction. Ultrason. Sonochem. 2018, 48, 453-462. [CrossRef]

75. Wang, Z.; Wang, C.; Zhang, C.; Li, W. Ultrasound-assisted enzyme catalyzed hydrolysis of olive waste and recovery of antioxidant phenolic compounds. Innov. Food Sci. Emerg. Technol. 2017, 44, 224-234. [CrossRef]

76. Mulinari, J.; Venturin, B.; Sbardelotto, M.; Dall Agnol, A.; Scapini, T.; Camargo, A.F.; Baldissarelli, D.P.; Modkovski, T.A.; Rossetto, V.; Dalla Rosa, C.; et al. Ultrasound-assisted hydrolysis of waste cooking oil catalyzed by homemade lipases. Ultrason. Sonochem. 2017, 35, 313-318. [CrossRef] [PubMed]

77. Fernández, M.L.Á.; Espino, M.; Gomez, F.J.V.; Silva, M.F. Novel approaches mediated by tailor-made green solvents for the extraction of phenolic compounds from agro-food industrial by-products. Food Chem. 2018, 239, 671-678. [CrossRef] [PubMed]

78. Huang, Y.; Feng, F.; Jiang, J.; Qiao, Y.; Wu, T.; Voglmeir, J.; Chen, Z.G. Green and efficient extraction of rutin from tartary buckwheat hull by using natural deep eutectic solvents. Food Chem. 2017, 221, 1400-1405. [CrossRef] [PubMed]

79. Mouratoglou, E.; Malliou, V.; Makris, D.P. Novel Glycerol-Based Natural Eutectic Mixtures and Their Efficiency in the Ultrasound-Assisted Extraction of Antioxidant Polyphenols from Agri-Food Waste Biomass. Waste Biomass Valoriz. 2016, 7, 1377-1387. [CrossRef]

80. Gonzales, G.B.; Smagghe, G.; Raes, K.; Van Camp, J. Combined alkaline hydrolysis and ultrasound-assisted extraction for the release of nonextractable phenolics from cauliflower (Brassica oleracea var. botrytis) waste. J. Agric. Food Chem. 2014, 62, 3371-3376. [CrossRef] [PubMed]

81. Burlini, I.; Grandini, A.; Tacchini, M.; Maresca, I.; Guerrini, A.; Sacchetti, G. Different strategies to obtain corn (Zea mays L.) germ extracts with enhanced antioxidant properties. Nat. Prod. Commun. 2020, 15, 1-9. [CrossRef]

82. Wu, D.; Gao, T.; Yang, H.; Du, Y.; Li, C.; Wei, L.; Zhou, T.; Lu, J.; Bi, H. Simultaneous microwave/ ultrasonic-assisted enzymatic extraction of antioxidant ingredients from Nitraria tangutorun Bobr. juice by-products. Ind. Crop. Prod. 2015, 66, 229-238. [CrossRef]

83. Xu, M.H.; Yang, X.Y.; Fu, M.R. Combined Ultrasonic and Microwave Method for Juglone Extraction from Walnut Green Husk (Juglone Nigra). Waste Biomass Valoriz. 2016, 7, 1159-1166. [CrossRef]

84. Liew, S.Q.; Ngoh, G.C.; Yusoff, R.; Teoh, W.H. Sequential ultrasound-microwave assisted acid extraction (UMAE) of pectin from pomelo peels. Int. J. Biol. Macromol. 2016, 93, 426-435. [CrossRef] 
85. Liu, Z.; Qiao, L.; Yang, F.; Gu, H.; Yang, L. Brönsted acidic ionic liquid based ultrasound-microwave synergistic extraction of pectin from pomelo peels. Int. J. Biol. Macromol. 2017, 94, 309-318. [CrossRef]

86. Cvjetko Bubalo, M.; Vidovic, S.; Radojčić Redovnikovic, I.; Jokic, S. New perspective in extraction of plant biologically active compounds by green solvents. Food Bioprod. Process. 2018, 109, 52-73. [CrossRef]

87. Kerton, F.M.; Mariotte, R. Alternative Solvents for Green Chemistry, 2nd ed.; Royal Society of Chemistry: Croydon, UK, 2013; pp. 1-325.

88. Chemat, F.; Rombaut, N.; Sicaire, A.G.; Meullemiestre, A.; Fabiano-Tixier, A.S.; Abert-Vian, M. Ultrasound assisted extraction of food and natural products. Mechanisms, techniques, combinations, protocols and applications. A review. Ultrason. Sonochem. 2017, 34, 540-560. [CrossRef] [PubMed]

89. Vilkhu, K.; Mawson, R.; Simons, L.; Bates, D. Applications and opportunities for ultrasound assisted extraction in the food industry-A review. Innov. Food Sci. Emerg. Technol. 2008, 9, 161-169. [CrossRef]

90. Kaufmann, B.; Christen, P. Recent Extraction Techniques for Natural Products: Microwave-assisted Extraction and Pressurised Solvent Extraction. Phytochem. Anal. 2002, 13, 105-115. [CrossRef] [PubMed]

91. Naviglio, D. Naviglio's Principle and Presentation of an Innovative Solid-Liquid Extraction Technology: Extractor Naviglio. Anal. Lett. 2003, 36, 1647-1659. [CrossRef]

92. Sapkale, G.N.; Patil, S.M.; Surwasee, U.S.; Bhatbhage, P.K. Supercritical fluid extraction-A Review. Int. J. Chem. Sci. 2010, 8, 729-743.

93. Nastic, N.; Švarc-Gajić, J.; Delerue-Matos, C.; Barroso, M.S.; Soares, C.; Moreira, M.M.; Morais, S.; Maškovic, P.; Srček, V.G.; Slivac, I.; et al. Subcritical water extraction as an environmentally-friendly technique to recover bioactive compounds from traditional Serbian medicinal plants. Ind. Crop. Prod. 2018, 111, 579-589. [CrossRef]

94. Abbott, A.P.; Capper, G.; Davies, D.L.; Rasheed, R.K.; Tambyrajah, V. Novel solvent properties of choline chloride/urea mixtures. Chem. Commun. 2003, 1, 70-71. [CrossRef]

95. Zainal-Abidin, M.H.; Hayyan, M.; Hayyan, A.; Jayakumar, N.S. New horizons in the extraction of bioactive compounds using deep eutectic solvents: A review. Anal. Chim. Acta 2017, 979, 1-23. [CrossRef]

96. Aroso, I.M.; Craveiro, R.; Rocha, Â.; Dionísio, M.; Barreiros, S.; Reis, R.L.; Paiva, A.; Duarte, A.R.C. Design of controlled release systems for THEDES-Therapeutic deep eutectic solvents, using supercritical fluid technology. Int. J. Pharm. 2015, 492, 73-79. [CrossRef]

97. Puri, M.; Sharma, D.; Barrow, C.J. Enzyme-assisted extraction of bioactives from plants. Trends Biotechnol. 2012, 30, 37-44. [CrossRef] [PubMed]

98. Sindhu, M.; Emilia, A. Ferulic acid: An antioxidant found naturally in plant cell walls and feruloyl esterases involved in its release and their applications. Crit. Rev. Biotechnol. 2004, 24, 59-83.

99. Balachandran, S.; Kentish, S.E.; Mawson, R.; Ashokkumar, M. Ultrasonic enhancement of the supercritical extraction from ginger. Ultrason. Sonochem. 2006, 13, 471-479. [CrossRef] [PubMed]

100. Zhou, Z.; Robards, K.; Helliwell, S.; Blanchard, C. The distribution of phenolic acids in rice. Food Chem. 2004, 87, 401-406. [CrossRef]

101. Acosta-Estrada, B.; Gutiérrez-Uribe, J.A.; Serna-Saldívar, S.O. Bound phenolics in foods, a review. Food Chem. 2014, 152, 46-55. [CrossRef] [PubMed]

102. Barberousse, H.; Roiseux, O.; Robert, C.; Paquot, M.; Deroanne, C.; Blecker, C. Analytical methodologies for quantification of ferulic acid and its oligomers. J. Sci. Food Agric. 2008, 88, 1494-1511. [CrossRef]

103. Wang, Z.; Li, S.; Ge, S.; Lin, S. A review of distribution, extraction methods and health benefits of bound phenolics in food plants. J. Agric. Food Chem. 2020, 68, 3330-3343. [CrossRef]

104. Geetha Balasubramaniam, V.; Ayyappan, P.; Sathvika, S.; Antony, U. Effect of enzyme preatrement in the ultrasound assisted extraction of finger millet polyphenols. J. Food Sci. Technol. 2019, 56, 1583-1594. [CrossRef]

105. Đurović, S.; Nikolić, B.; Luković, N.; Jovanović, J.; Stefanović, A.; Šekuljica, N.; Mijin, D.; Knežević-Jugović, Z. The impact of high-power ultrasound and microwave on the phenolic acid profile and antioxidant activity of the extract from yellow soybean seeds. Ind. Crop. Prod. 2018, 122, 223-231. [CrossRef]

106. Prado, J.M.; Veggy, P.C.; Maireles, M.A.A. Scale-Up Issues and Cost of Manufacturing Bioactive Compounds by Supercritical Fluid Extraction and Ultrasound Assisted Extraction; Global Food Security and Wellness; Springer: New York, NY, USA, 2017; pp. 377-433.

(C) 2020 by the authors. Licensee MDPI, Basel, Switzerland. This article is an open access article distributed under the terms and conditions of the Creative Commons Attribution (CC BY) license (http://creativecommons.org/licenses/by/4.0/). 